\title{
Multi-step regioselectivity and non-Kirkendall anion exchange of copper chalcogenide nanorods.
}

Luis F. Garcia-Herrera, Haley P. McAllister, Huiyan Xiong, Haiying Wang, ${ }^{\S}$ Robert W. Lord, ${ }^{\dagger}$ Sarah K. $\mathrm{O}^{\prime}$ Boyle,$^{\dagger}$ Adem Imamovic, Benjamin C. Steimle, ${ }^{\dagger}$ Raymond E. Schaak, ${ }^{\dagger}$ and Katherine E. Plass*

Department of Chemistry, Franklin \& Marshall College, Lancaster, Pennsylvania 17604, United States

${ }^{\dagger}$ Department of Chemistry, The Pennsylvania State University, University Park, Pennsylvania 16802, United States

${ }^{\S}$ Materials Characterization Laboratory, The Pennsylvania State University, University Park, Pennsylvania 16802, United States

†Department of Chemistry, Department of Chemical Engineering, Materials Research Institute, The Pennsylvania State University, University Park, Pennsylvania 16802, United States

$\begin{array}{lr}\text { ADDITIONAL DATA } & 2\end{array}$

EDS spectra of unexchanged and near-fully exchanged nanorods $\quad 2$

Comparison of the $\alpha$-chalcocite and weissite crystal structures $\quad 2$

Structure comparisons between $\alpha$-chalcocite and roxbyite and its effect on anion exchange 3

$\begin{array}{lr}\text { Copper telluride crystal structure assignment } & 3\end{array}$

Additional microscopy data $\quad 4$

$\begin{array}{lr}\text { REFERENCES } & 6\end{array}$ 
ADDITIONAL DATA

EDS spectra of unexchanged and near-fully exchanged nanorods
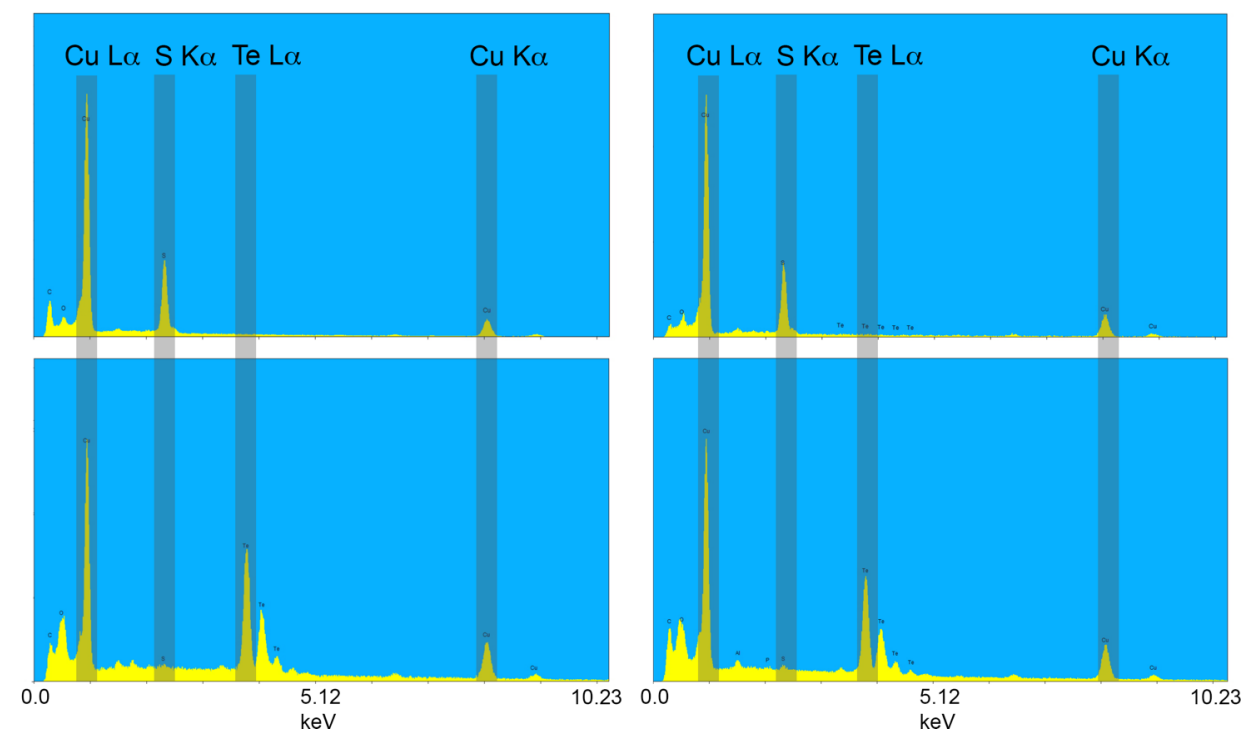

Figure S1. SEM-EDS spectra for two examples of $\alpha$-chalcocite nanorods before (top) and after (bottom) Te-exchange showing the trace amount of sulfur remaining after exchange at $260^{\circ} \mathrm{C}$ for 2 hours (left) or $75 \mathrm{~min}$ (right).

\section{Comparison of the $\alpha$-chalcocite and weissite crystal structures}

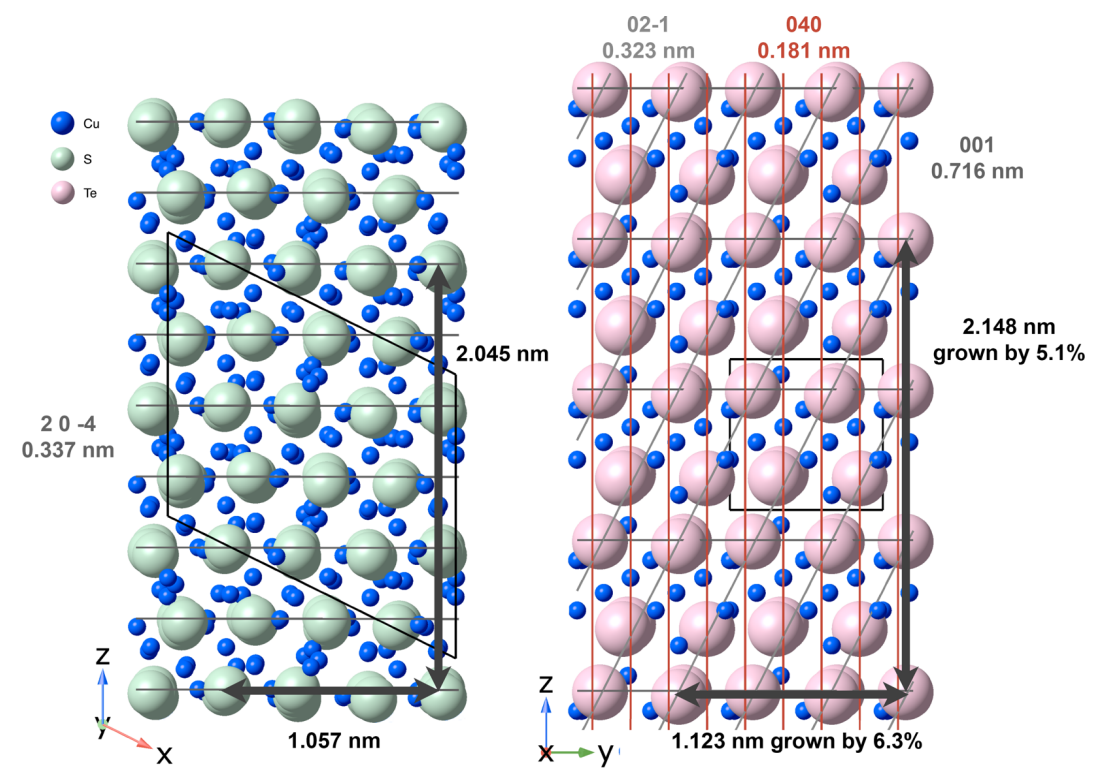

Figure S2. Comparison of the $\alpha$-chalcocite (ICSD 100333)1 (left) and weissite ${ }^{2,3}$ (right) crystal structures with measurements to illustrate the expected particle size expansion and lattice spacings that are observed in the HR-TEM. 

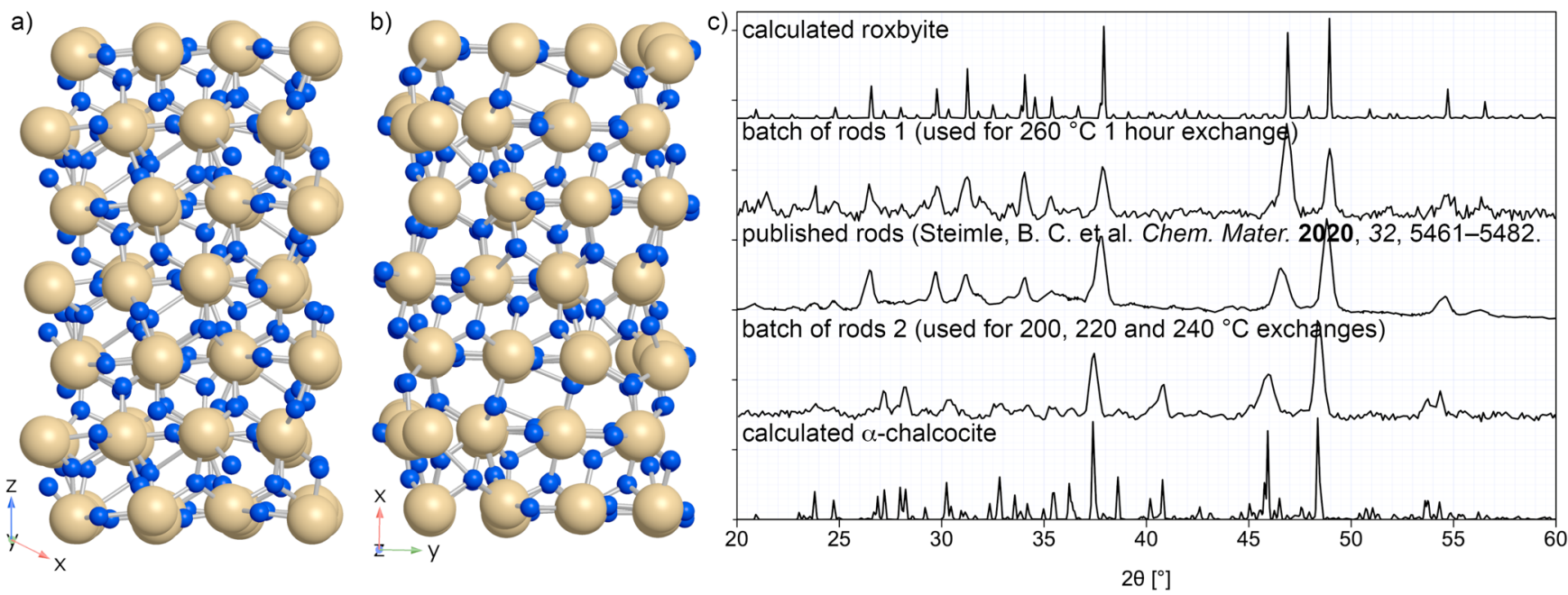

Figure S3. Structures of a) $\alpha$-chalcocite (ICSD 100333) ${ }^{1}$ and b) roxbyite (ICSD 185807) ${ }^{4}$ showing the similar close-packing with variations in the cation positions. $\mathrm{Cu}$ atoms are blue and $\mathrm{S}$ atoms are yellow. $\mathrm{Cu}-\mathrm{S}$ bonds are shown. The synthetic route reported for roxbyite nanorods $\mathrm{s}^{5,6}$ frequently afforded the structurally similar $\alpha$-chalcocite instead. c) Comparison of the calculated and experimental PXRD patterns, showing the difference between two batches of nanorods, one of which matches $\alpha$-chalcocite and the other of which matches roxbyite. Furthermore, we see a comparison with a published pattern for rods using the same synthetic procedure showing roxbyite formation.
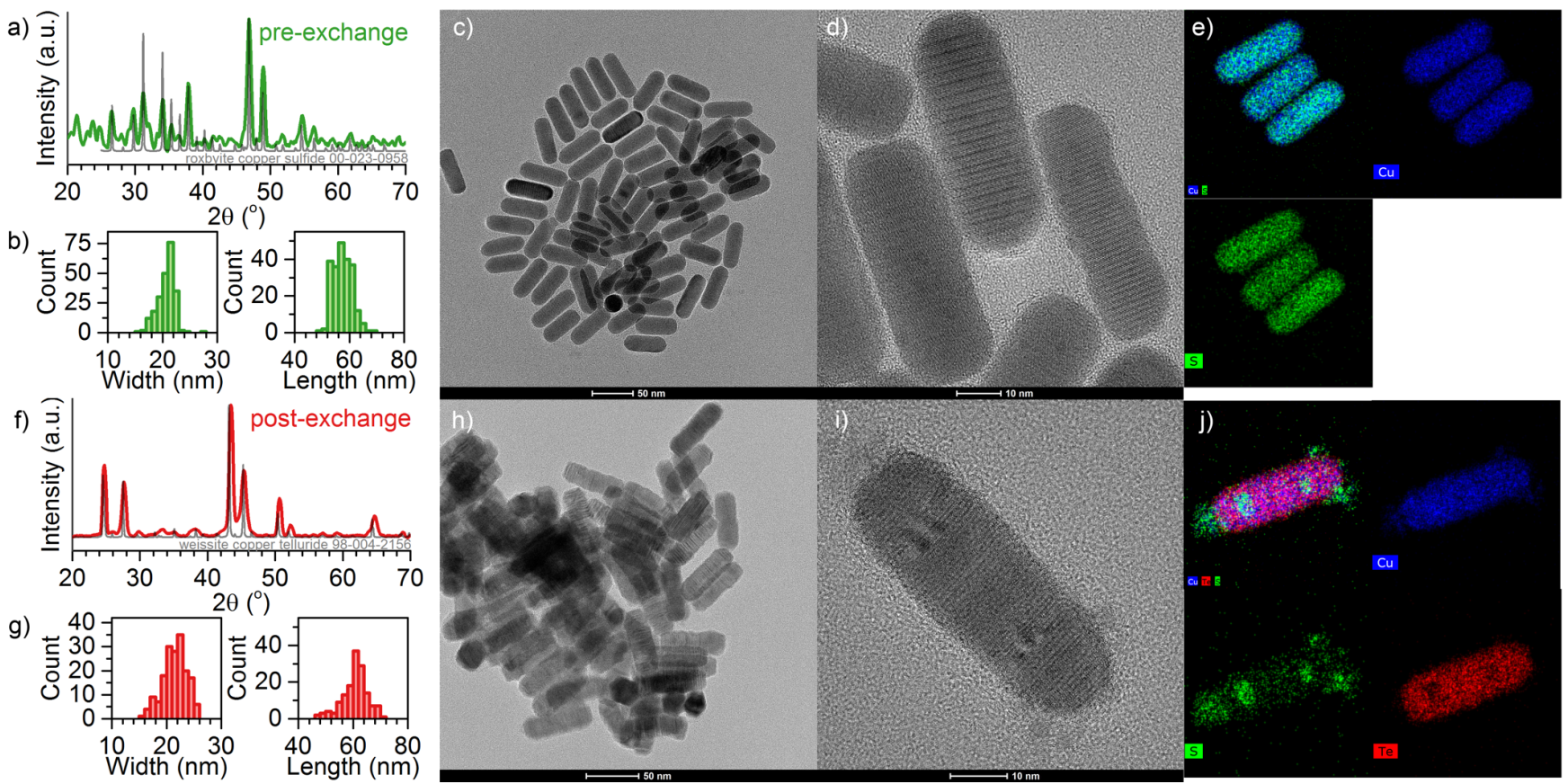

Figure S4. Initial roxbyite nanorods (a-e) compared with the tellurium-exchanged rods after 1 hour of Te=TOP exposure at $260{ }^{\circ} \mathrm{C}(\mathrm{f}-\mathrm{j}) . \mathrm{PXRD}(\mathrm{a}, \mathrm{f})$ establishes that the roxbyite $\mathrm{Cu}_{2-\mathrm{x}} \mathrm{S}$ crystal structure transforms to the weissite $\mathrm{Cu}_{2-\mathrm{x}} \mathrm{Te}$ structure without alteration of the size or aspect ratio of the rods ( $b$, g and c, h). HR-TEM (d, i) establish that the crystallinity is maintained, despite the existence of domains of $\mathrm{Cu}_{2-\mathrm{x}} \mathrm{S}$ within the exchanged particles, further illustrated by the EDS maps $(e, j)$.

\section{Copper telluride crystal structure assignment}

Copper telluride crystal structure assignment is complicated, as discussed in detail in a recent theoretical study by Yu et al.. ${ }^{2}$ They carried out calculations on four basic structure types (the hexagonal or Nowotny phase, as well as a trigonal, monoclinic, and tetragonal phase) and compared it with reported PXRD data. Notably, they found a discrepancy between the PXRD derived from their calculated Nowotny phase and PXRD database entries attributed to this phase. The PXRD data was a better match to their calculated trigonal phase, which was consistent with their determination that for $\mathrm{Cu}$-deficient weissite $\left(\mathrm{Cu}_{2-\mathrm{x}} \mathrm{Te}\right.$ with $\left.\mathrm{x} \geq 0.125\right)$, the trigonal phase was the most stable. The experimental PXRD pattern obtained after Te-exchange here matched many ICDD database entries consistent with the mis-assigned Nowotny phase, exhibiting prominent reflections at 43.0 and $45.5^{\circ} 20$. It also matched entry $98-004-2156$, which was derived from a trigonal crystal structure (entry 42156 in the ICSD), so this was used for comparison in Figures 1, 2, 3, and S2. This model, however, showed unusual close Te-Te interactions and 
the pattern of two closely spaced Te-layers separated by two more separated layers was not observed in the HR-TEM. The experimental copper telluride PXRD pattern below is compared with the pattern generated by the four crystal structures reported by Yu et al., as well as two representative structures from the ICSD, and a structure from Lord et al., ${ }^{3}$ which slightly altered the trigonal structure from Yu et al. to correct overlapping atoms. Ultimately, the Lord et al. structure was used as the model presented in Schemes 1 and 2 and Figure S4 as the highest-quality crystal structure consistent with the PXRD data and the HR-TEM.

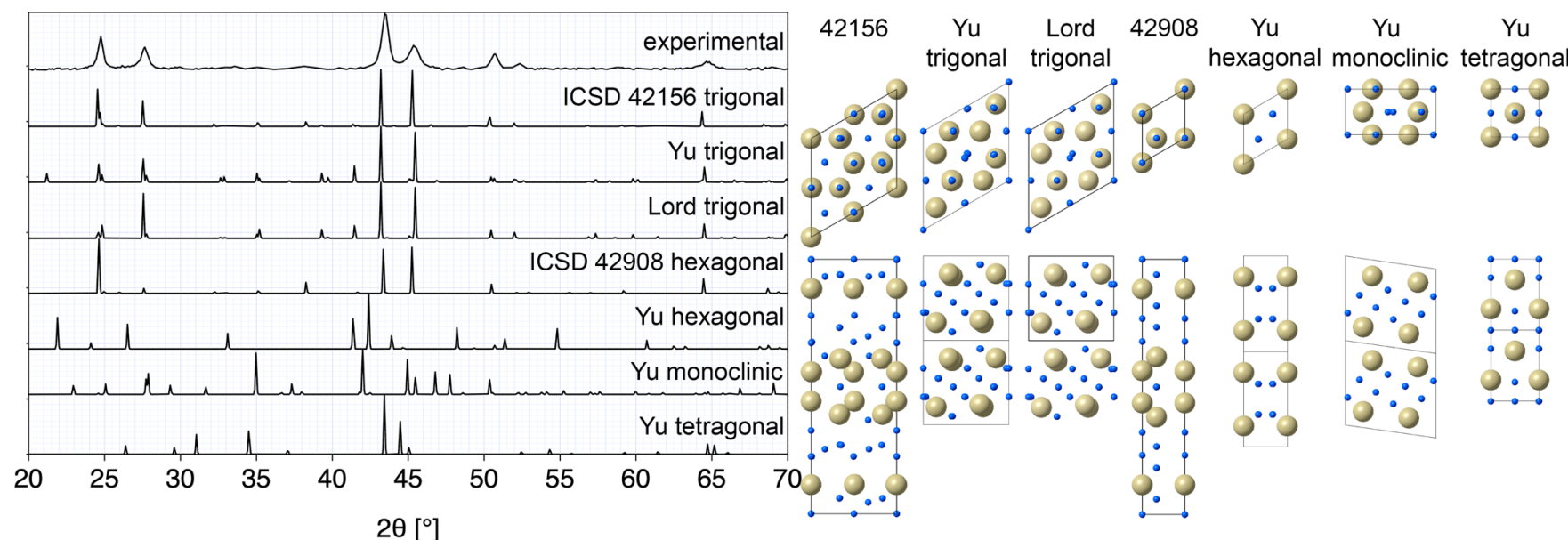

Figure S5. Comparison of the experimental PXRD pattern obtained post-anion exchange and the calculated PXRD patterns of various copper telluride phases (left). The crystal structures are shown (right) along the c-axis (top) and b-axis (bottom).

\section{Additional microscopy data}
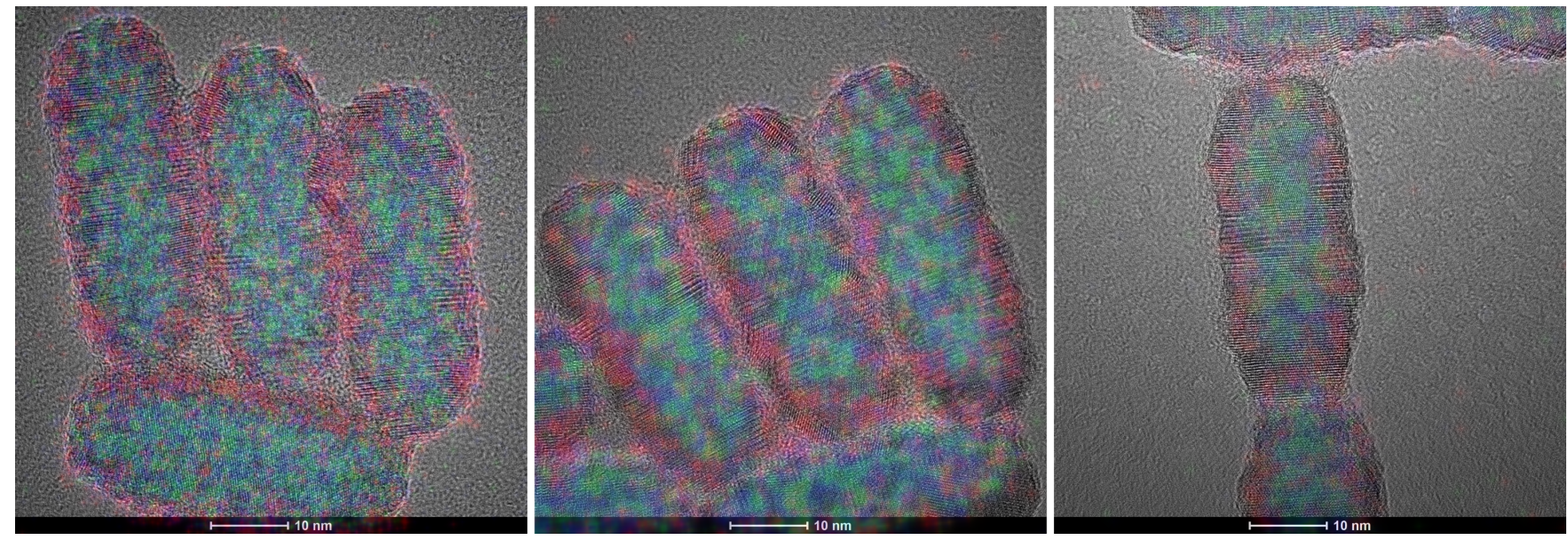

Figure S6. HR-TEM images with overlaid STEM-EDS map of nanorods that were tellurium-exchanged at $200^{\circ} \mathrm{C}$ for $20 \mathrm{~min} . \mathrm{Cu}=\mathrm{blue}, \mathrm{Te}=\mathrm{red}$, and $\mathrm{S}=$ green. The $\mathrm{Cu}_{2-\mathrm{x}} \mathrm{S} / \mathrm{Cu}_{2-\mathrm{x}} \mathrm{Te}$ core/shell structure is evident. The shell of $\mathrm{Cu}_{2-\mathrm{x}} \mathrm{Te}$ is apparent in a continguous crystal structure with increased lattice spacing on the sides of the rods. This crystalline region of $\mathrm{Cu}_{2-x} \mathrm{Te}$ propagates perpendicular to the side of the rods unevenly.
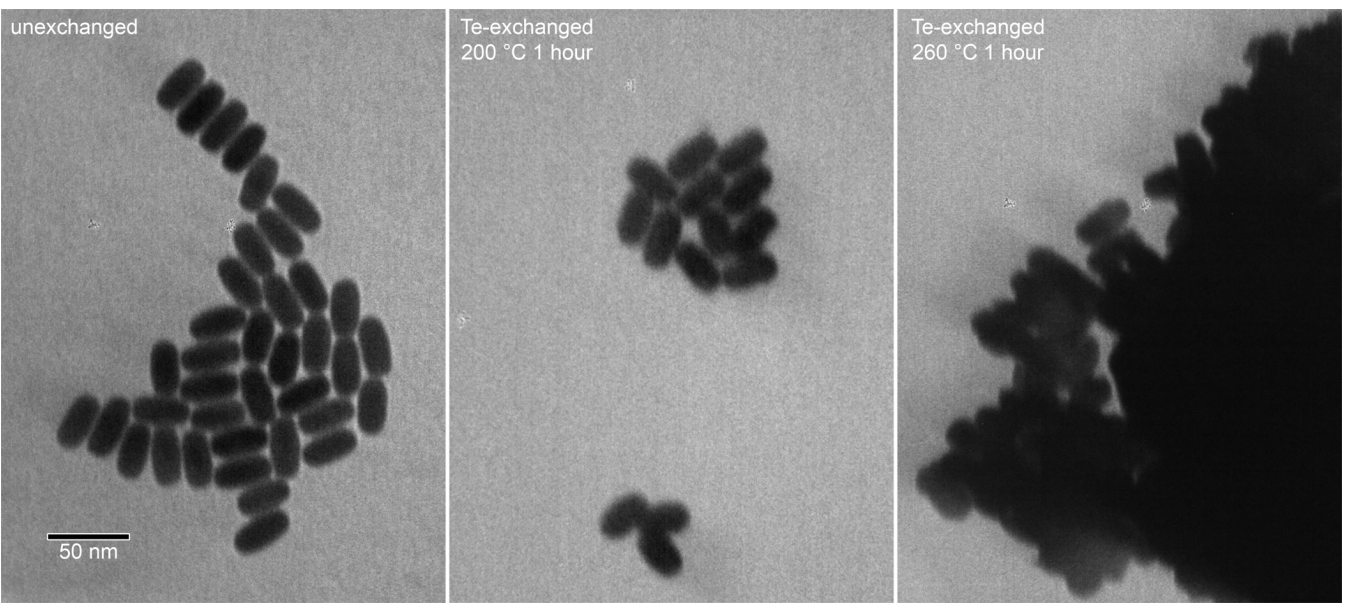

Figure S7. Low resolution TEM demonstrating increasing aggregation with increasing extent of anion exchange due to removal of some surface ligands. 


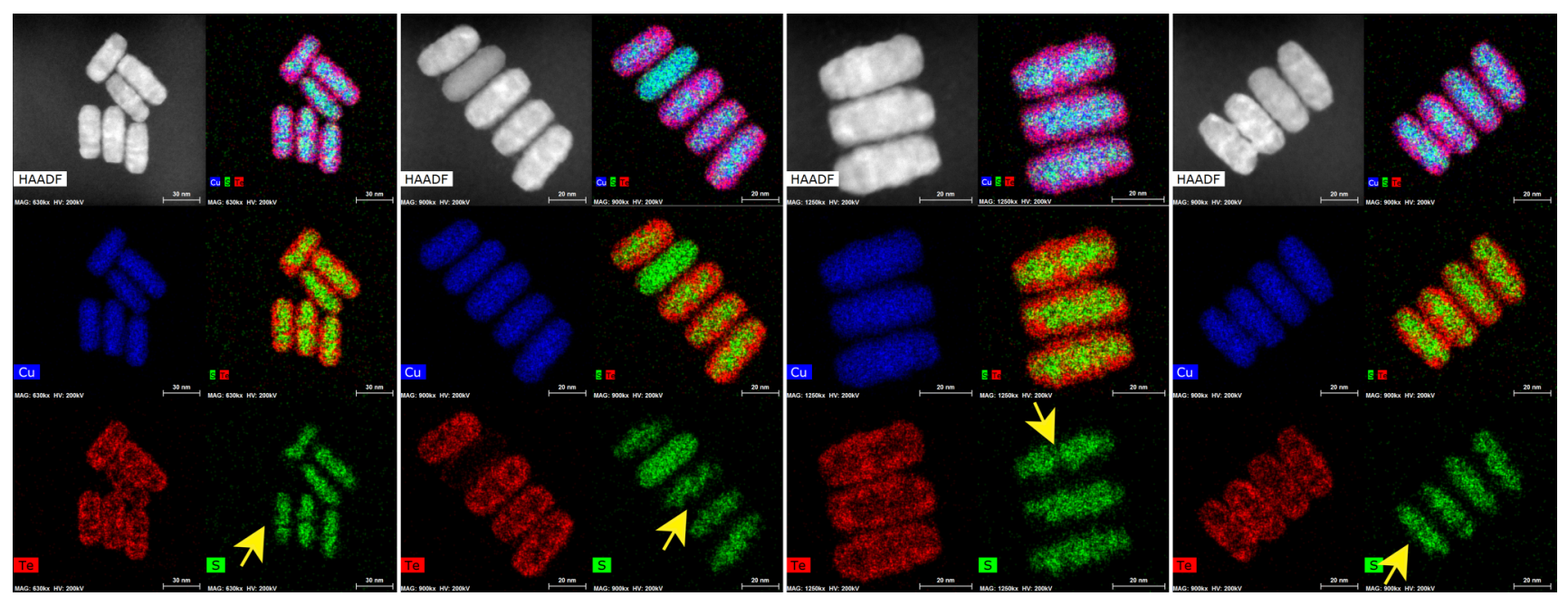

Figure S8. STEM-EDS maps of four different sets of nanorods, tellurium-exchanged at $200^{\circ} \mathrm{C}$ for 1 hour. $\mathrm{Cu}=\mathrm{blue}, \mathrm{Te}=\mathrm{red}$, and $\mathrm{S}=\mathrm{green}$. The $\mathrm{Cu}_{2-\mathrm{x}} \mathrm{S} / \mathrm{Cu}_{2-\mathrm{x}} \mathrm{Te}$ core/shell structure is evident, as are the lines of $\mathrm{Cu}_{2-\mathrm{x}} \mathrm{Te}$ that propagate perpendicular to the side of the rods (indicated with yellow arrows in the $S$ image).

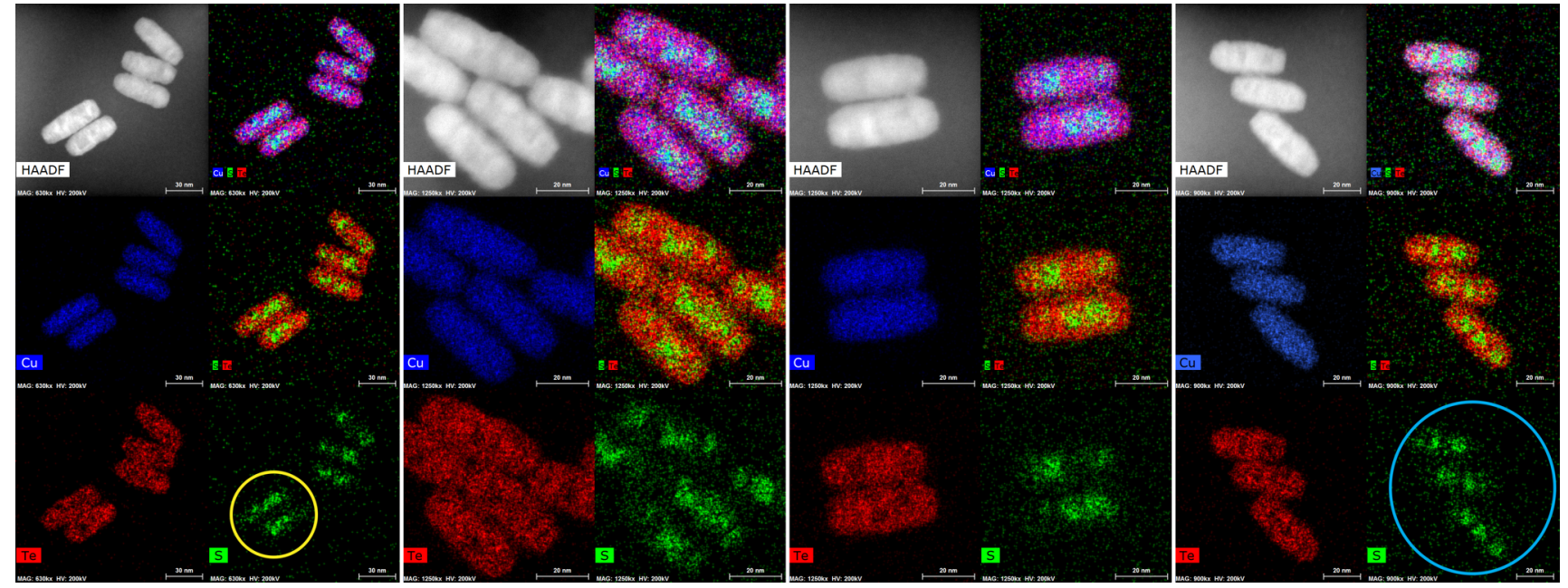

Figure S9. STEM-EDS maps of four different sets of nanorods, tellurium-exchanged at $220^{\circ} \mathrm{C}$ for 1 hour. $\mathrm{Cu}=\mathrm{blue}, \mathrm{Te}=\mathrm{red}$, and $\mathrm{S}=\mathrm{green}$. The rods exhibit a mixture of $\mathrm{Cu}_{2-\mathrm{x}} \mathrm{S} / \mathrm{Cu}_{2-\mathrm{x}} \mathrm{Te}$ core/shell structures (yellow circles) and rods where Te-exchange perpendicular to the side of the rods has progressed to the point where regions of $\mathrm{Cu}_{2-\mathrm{x}} \mathrm{Te}$ separate multiple, irregular $\mathrm{Cu}_{2-\mathrm{x}} \mathrm{S}$ domains (cyan circle).

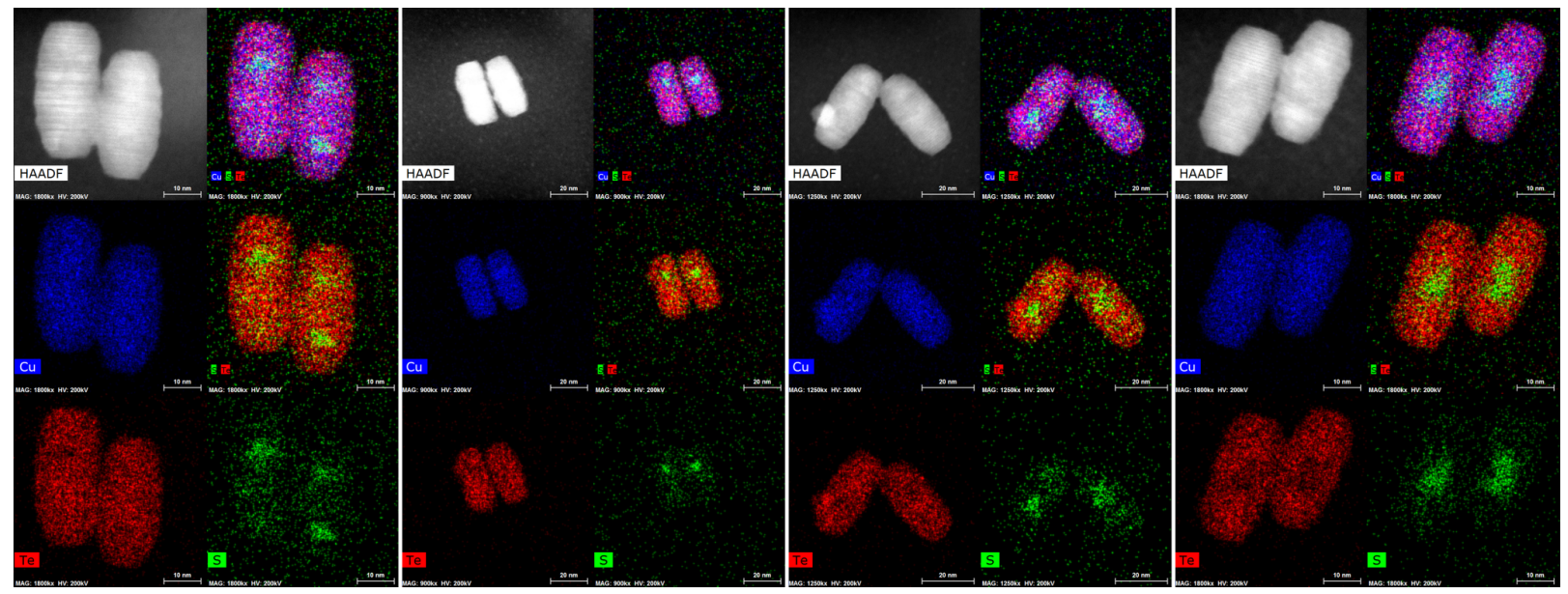

Figure S10. STEM-EDS maps of four different sets of nanorods, tellurium-exchanged at $240{ }^{\circ} \mathrm{C}$ for 1 hour. $\mathrm{Cu}=\mathrm{blue}, \mathrm{Te}=\mathrm{red}$, and $\mathrm{S}=\mathrm{green}$. The rods now show one or two domains of $\mathrm{Cu}_{2-\mathrm{x}} \mathrm{S}$ embedded in rods primarily consisting of $\mathrm{Cu}_{2-\mathrm{x}} \mathrm{Te}$. 

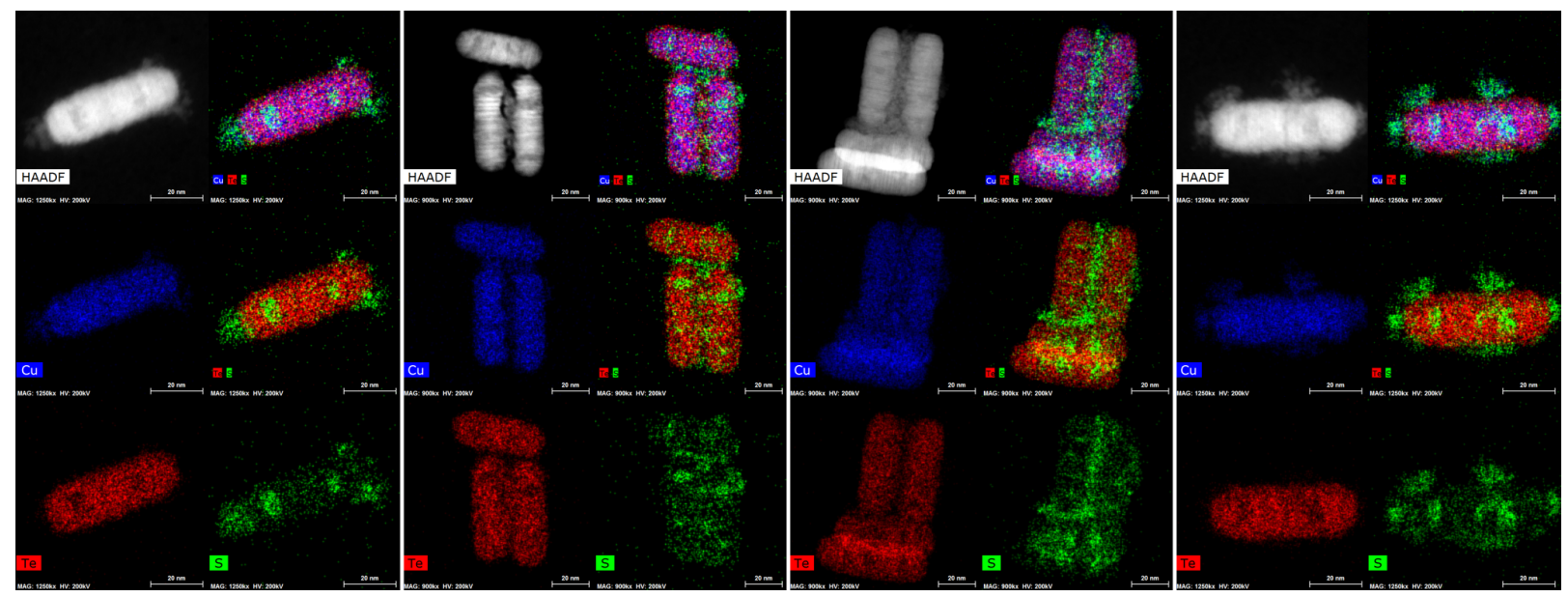

Figure S11. STEM-EDS maps of four different sets of nanorods, tellurium-exchanged at $260^{\circ} \mathrm{C}$ for 1 hour. $\mathrm{Cu}=\mathrm{blue}, \mathrm{Te}=\mathrm{red}$, and $\mathrm{S}=\mathrm{green}$. The rods now show two domains of $\mathrm{Cu}_{2-x} \mathrm{~S}$, one at either end of the rod, embedded in rods primarily consisting of $\mathrm{Cu}_{2-\mathrm{x}} \mathrm{Te}$. Note that this particular batch of samples shows redeposition of sulfur-rich copper sulfide outside of the particles. This both demonstrates that copper is removed in the exchange process and provides a comparison of redeposited copper sulfide on the outside of the particle with the double cores of copper sulfide within the particle, which are accompanied by lower Te density.

\section{REFERENCES}

(1) Evans, H. T. The crystal structures of low chalcocite and djurleite. Z. Kristallogr. Cryst. Mater. 1979, 150, 299-320.

(2) Yu, L.; Luo, K.; Chen, S.; Duan, C.-G. Cu-deficiency induced structural transition of Cu $\mathrm{u}_{2-\mathrm{x}}$ Te. CrystEngComm 2015, 17, 2878-2885.

(3) Lord, R. W.; Fanghanel, J.; Holder, C. F.; Dabo, I.; Schaak, R. E. Colloidal Nanoparticles of a Metastable Copper Selenide Phase with Near-Infrared Plasmon Resonance. Chem. Mater. 2020, 32, 10227-10234.

(4) Mumme, W. G.; Gable, R. W.; Petricek, V. The crystal structure of roxbyite, $\mathrm{Cu}_{58} \mathrm{~S}_{32}$. Can. Mineral 2012, 50, $423-430$.

(5) Fenton, J. L.; Steimle, B. C.; Schaak, R. E. Tunable intraparticle frameworks for creating complex heterostructured nanoparticle libraries. Science 2018, 360, 513-517.

(6) Zhai, Y.; Shim, M. Effects of copper precursor reactivity on the shape and phase of copper sulfide nanocrystals. Chem. Mater. $2017,29,2390-2397$.

(7) Steimle, B. C.; Fagan, A. M.; Butterfield, A. G.; Lord, R. W.; McCormick, C. R.; Di Domizio, G. A.; Schaak, R. E. Experimental Insights into Partial Cation Exchange Reactions for Synthesizing Heterostructured Metal Sulfide Nanocrystals. Chem. Mater. 2020, 32, 5461-5482. 